\title{
Follow-up efficacy of physical exercise interventions on fall incidence and fall risk in healthy older adults: a systematic review and meta-analysis
}

\author{
Azza Hamed ${ }^{1,2,3}$ (D), Sebastian Bohm ${ }^{1,2^{*}}$ (D) Falk Mersmann ${ }^{1,2}$ (D) and Adamantios Arampatzis , $^{1,2^{*}}$ (D)
}

\begin{abstract}
Background: The risk of falling and associated injuries increases with age. Therefore, the prevention of falls is a key priority in geriatrics and is particularly based on physical exercising, aiming to improve the age-related decline in motor performance, which is crucial in response to postural threats. Although the benefits and specifications of effective exercise programs have been well documented in pre-post design studies, that is during the treatment, the definitive retention and transfer of these fall-related exercise benefits to the daily life fall risk during follow-up periods remains largely unclear. Accordingly, this meta-analysis investigates the efficacy of exercise interventions on the follow-up risk of falling.
\end{abstract}

Methods: A systematic database search was conducted. A study was considered eligible if it examined the number of falls (fall rate) and fallers (fall risk) of healthy older adults ( $\geq 65$ years) during a follow-up period after participating in a randomized controlled physical exercise intervention. The pooled estimates of the fall rate and fall risk ratios were calculated using a random-effects meta-analysis. Furthermore, the methodological quality and the risk of bias were assessed.

Results: Twenty-six studies with 31 different intervention groups were included (4739 participants). The number of falls was significantly $(p<0.001$ ) reduced by $32 \%$ (rate ratio $0.68,95 \%$ confidence interval 0.58 to 0.80 ) and the number of fallers by $22 \%$ (risk ratio $0.78,95 \%$ confidence interval 0.68 to 0.89 ) following exercising when compared with controls. Interventions that applied posture-challenging exercises showed the highest effects. The methodological quality score was acceptable $(73 \pm 11 \%)$ and risk of bias low.

Conclusions: The present review and meta-analysis provide evidence that physical exercise interventions have the potential to significantly reduce fall rate and risk in healthy older adults. Posture-challenging exercises might be particularly considered when designing fall prevention interventions.

Keywords: Fall prevention, Physical training interventions, Older adults, Fall risk, Fall incidence, Postural and balance perturbations

\footnotetext{
*Correspondence: sebastian.bohm@hu-berlin.de; a.arampatzis@hu-berlin.de; https://www.dtms.hu-berlin.de

${ }^{1}$ Department of Training and Movement Sciences, Humboldt-Universität zu

Berlin, Philippstr. 13, Haus 11, 10115 Berlin, Germany

Full list of author information is available at the end of the article
} 


\section{Key points}

Physical exercise clearly reduces the follow-up risk of falling.

Exercise interventions for fall prevention may include stability-challenging conditions and perturbations.

Specification of such exercises (alongside intensity) and understanding of their physiological underlying effect is needed to ensure and improve effective retention of fall-related exercise benefits in the post intervention follow-up.

\section{Background}

Aging is associated with a reduction of the functional and physiological capacity of the musculoskeletal and central nervous systems, which significantly affects motor performance [1-4]. It is well evidenced that these age-related declines increase the incidence of falls and re-falls among older people [5], with one third of older adults above 65 years falling at least once a year $[6,7]$ and increasing fall rates in even older ages [8-10]. Falls in older adults occur mainly during dynamic daily tasks (e.g., walking and initiation of walking, and sitting down or lowering) and in the absence of external events [11-13], which indicates a reduced ability of effective internal control and execution of regular dynamic movements. In the face of external hazards that occur during daily life tasks, such impairments of motor responses lead to even higher risk of stability loss [14-17]. When postural/dynamic stability cannot be maintained and a fall event occurs, injury incidence is particularly high in older adults. Falls are one of the leading causes of injury-related hospital admissions in this age group [18] and are often followed by functional dependence, serious or fatal injuries, fractures, and high morbidity [19].

The decline in motor performance is caused by diverse age-related changes across the many different levels of the human organism, e.g., central nervous and musculoskeletal. Among others, muscle weakness with aging, so-called sarcopenia [20], is a key factor that determines stability control and recovery responses following sudden threats [21-25]. The loss of muscle mass, which occurs due to a reduced number of motor units and size of single muscle fibers, as well as a decrease of voluntary activation [26-30], leads to a decline of the muscle force capacity [1, 2, 28, 31, 32]. As degenerative effects predominantly affect fast twitch fibers [33] and muscle fascicle length decreases as well [34], the mechanical power (product of force and velocity) as a predictor of the muscle's functional capacity during dynamic stability threats [35] is affected in a twofold manner [36, 37]. Consequently, studies [21, 22] have demonstrated deficits in the execution of fundamental stability control mechanisms (e.g., modulation of the base of support and counter segment rotations around the center of mass [38]) in older adults, which likely contributes to the limited ability to regain stability following sudden unstable conditions [22].

Current reviews and guidelines regarding the prevention of falls consistently recommend physical exercises [39-43] using strength, balance, mobility, and perturbation training paradigms $[40,43-45]$ to counteract the decline of motor performance. Moreover, Tai Chi contains balance-challenging slowly performed movements and has been recommended for fall prevention in older adults $[46,47]$. In fact, the body of randomized controlled trials shows that training of this kind in healthy older adults has the potential to improve strength [48-52], mobility $[48,52]$, stability, and balance control $[50,52,53]$ and reduce the risk of falling [54] and related injuries [40, $49,55,56]$, within and after the intervention period [52, 57, 58]. Previous meta-analyses allowed for conclusions on the most effective characteristics of exercise training interventions with respect to the reduction of the risk of falling $[44,59,60]$. However, these meta-analyses did not distinguish between studies that assessed the effects occurring during the intervention time and studies that assessed only the follow-up period, i.e., after finishing the treatment. Thus, the question of how much of these benefits of training persist over a longer time period and transfer to daily life after completion (i.e., follow-up effects) is still not fully understood. As motor learning and neuromuscular plasticity in older adults is largely preserved [61-67], older adults are capable of an improvement and long-term retention of effective stability control mechanisms as well as gains in functional capacities, both of which are necessary to compensate for challenging balance conditions $[64,68]$. Therefore, it can be argued that exercise interventions may improve relevant key factors of successful reactive postural responses to sudden postural threats occurring during daily life. However, although there is broad evidence on acute fall-related benefits of exercise interventions (e.g., strength gains, stability control improvements) $[40,44,49,55,56,69]$, little is known about how fall prevention interventions actually translate into a reduction of falls in time periods after participation, i.e., retention or follow-up. Further, the small sample sizes and diverse exercise approaches compromise the conclusions drawn from single randomized controlled trials.

The scope of the current review is to provide an analysis of healthy older adults whose fall occurrences are not co-affected by an additional factor, i.e., a particular pathology. Some impairments may affect the physiological responsiveness to the training or would require adjusted exercise delivery strategies (e.g., group sizes and supervision). Consequently, to avoid a bias due to factors other than aging on the efficacy of physical exercise interventions for post intervention fall prevention, we included only healthy older adults in the 
present review and meta-analysis. Therefore, the purpose of the present review and meta-analysis was to investigate the efficacy of physical exercise interventions on post intervention fall prevention in healthy older adults (i.e., without neurological disease [e.g., Parkinson's disease, stroke, or dementia/cognitive impairment], serious visual impairments [e.g., cataract, glaucoma, or color blindness], severe cardiac, pulmonary or musculoskeletal disorders, and severe osteoporosis, not living independently and not taking psychotropic drugs, that could influence fall outcomes). We searched for randomized controlled trials, examining the effect of different types and forms of physical exercises on fall rate (i.e., number of fall events) and fall risk (i.e., number of fallers) during the follow-up period. For the respective studies, we calculated the weighted average effect sizes and assessed the study quality and risk of bias.

\section{Methods}

\section{Search strategy}

Three electronic bibliographic databases (Web of Science, MEDLINE, and Scopus) were systematically searched (from inception till August 2018) using a combined set of terms related to physical exercises (interventions, exercises, exercising, training), older adult subjects (elderly, old, aged, age, senior, geriatric, aging, ageing) and falls (accidental fall, falling, slip, tripping) (see Additional file 1). Each term was mapped to $\mathrm{MeSH}$ (Medical Subject Headings) and controlled terms if available. Moreover, the reference lists of the eligible studies and of previous meta-analyses were screened for additional suitable titles.

\section{Study inclusion and exclusion criteria}

The search results were evaluated at first by screening the study titles. Thereafter, abstracts and further the full texts were examined to determine their eligibility. A study was included when the following inclusion criteria were fulfilled: (a) investigation of fall incidence (fall rate) and/or number of fallers (fall risk) during (b) a follow-up period (started from the intervention's end point) of at least 6 months after (c) a longitudinal (d) randomized controlled (level I) (e) physical exercise intervention (f) of at least 4 weeks on (g) healthy, (h) older adults ( $\geq 65$ years). Studies which did not meet the inclusion criteria in this stage were excluded, and the respective exclusion reason was documented (Fig. 1). Finally, the reference lists of the eligible studies and of previous meta-analyses were screened for further articles. When a study presented different groups or intervention types and some of those did not meet the criteria, only the group or intervention that fulfilled the

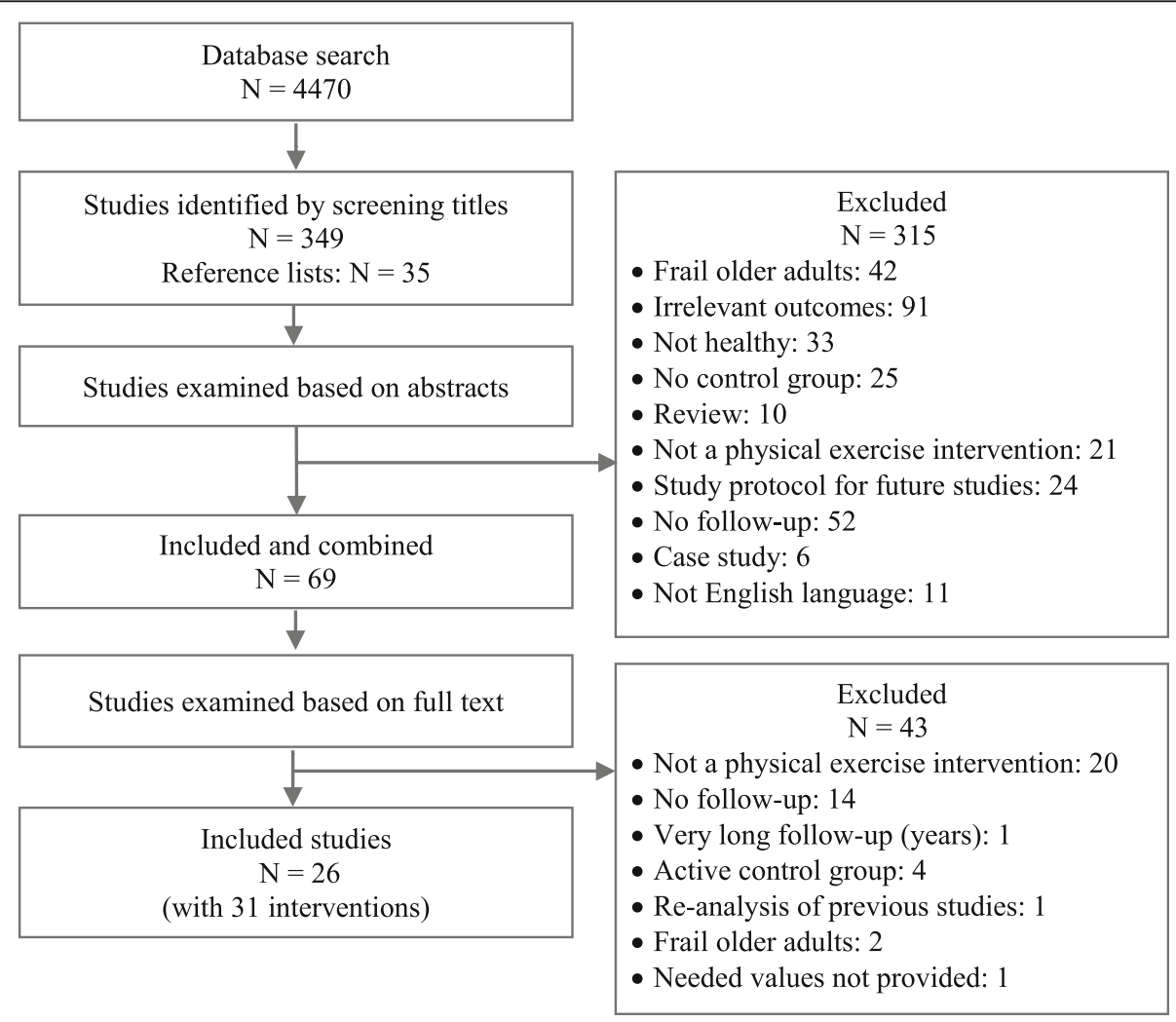

Fig. 1 Flowchart of the systematic review process 
criteria was included. If an eligible study reported two or more interventions of different types of physical exercises, each intervention group was included separately. Note that studies with different follow-up durations and different exercise interventions were included, which might cause heterogeneity. The systematic review process of the present meta-analysis is presented in Fig. 1.

\section{Study quality assessment and risk of bias}

We customized a methodological quality scale to assess the internal, statistical, and external validity of the included studies with regard to the concept of the present meta-analysis (Table 1). A positive point was assigned to each quality criterion if it was fulfilled. The quality score of each validity aspect (i.e., internal, statistical, and external) was expressed as the number of items with a positive score in percent of the total number of items. Thus, $100 \%$ indicates highest possible quality. The single section scores were then averaged to calculate the overall methodological quality of each study. However, a low result in the rating was not an exclusion criterion but allowed for an adequate interpretation of the single study outcomes in the context of the scope of the current meta-analysis. The calculation of the quality score of each validity section was done by counting the number of items with positive signs and dividing them by the total numbers of items to be expressed finally as a percentage. The single section scores were then averaged to calculate the overall methodological quality of each study.

The risk of bias for each study was examined according to the Cochrane risk of bias tool [70] in which the following bias items were assessed: sequence generation, allocation concealment, blinding of participants and outcome assessors, incomplete outcome data, selective outcome reporting, and other sources of bias. The publication bias was tested by means of Egger's test [71].

\section{Data extraction}

The data of interest were extracted and organized in a table including all of the following information: authors' names, participants' characteristics (age, sex, and number), exercise protocol (type and description of exercises), intervention characteristics, and duration of follow-up period (for studies with more than one follow-up time point the latest one was chosen) as well as the main outcomes. If the outcome parameters (i.e., number of falls and number of fallers) were not reported in appropriate format (e.g., percentages, odds ratio, hazard ratio, or presented as a graph), the corresponding authors were contacted and asked to provide the missing values. Extracting the values visually from a graph was the last option. To avoid double inclusion of the same participants, one study [72] was excluded from the analysis as the data of the same participants were re-analyzed already in another included study [73] as stated by the authors.

\section{Statistical analysis}

The fall rate (i.e., number of falls) and fall risk (i.e., number of fallers) were calculated from the completion time point of the intervention program until the end of the follow-up duration as a fall incidence rate ratio (value of intervention group divided by value of control group) and risk ratio for each study, respectively. The risk ratio was considered to account for the effect of multiple falls (more than one fall per person) [74] on fall rate ratio. Thus, a fall rate ratio and/or risk ratio below the value of one means lower risk in the intervention group than the untreated control group, while a value higher than one indicates a higher risk in the intervention group. The relative risk reduction was used to re-express the risk ratio and rate ratio as percentage reduction in number of fall events and number of fallers [75]. If the fall rate ratio or fall risk ratio were reported without the raw values of fall events and fallers [76-79], the ratios were taken directly from the respective study and the standard error was calculated from the $95 \%$ confidence intervals.

The single data were then pooled in a meta-analysis to estimate the effect sizes as weighted average overall fall rate and risk ratios, respectively. For this reason, a random-effects model of the generic inverse variance method was used because it gives more weight to the studies with small standard errors and takes into consideration the heterogeneity of the included studies $[80,81]$. The presence of an overall effect of a physical exercise intervention on fall rate ratio and risk ratio during follow-up was tested accordingly [70]. The meta-analysis statistics and respective forest plots were performed using the software Review Manager (Version 5.2. Copenhagen: The Nordic Cochrane Centre, the Cochrane Collaboration, 2014).

\section{Results}

\section{Review statistics}

A total number of 4470 studies were recorded after the database search (Fig. 1). The study titles were then checked for eligibility and at the same time, the duplicates were removed, yielding 349 potentially eligible studies. By reviewing the abstracts, the number of potentially eligible studies was 34. After reviewing the full text, 24 studies remained included. Screening of the reference lists of the included studies and of previous meta-analyses yielded an additional 35 related studies from which only two studies were eligible after checking the abstract and the full text. Finally, 26 studies were included in the current meta-analysis 
Table 1 Criteria of methodological quality

\begin{tabular}{|c|c|}
\hline Internal validity & Scoring \\
\hline 1. Study design & $\begin{array}{l}\text { A positive point was assigned if the following aspects were considered } \\
1 \text { Number of falls as an outcome measure } \\
2 \text { Number of fallers as an outcome measure } \\
3 \text { Healthy and not frail elderly } \\
4 \text { Follow-up period } \geq 6 \text { months } \\
5 \text { Control group }\end{array}$ \\
\hline 2. Methods & A positive point was assigned if the following aspects were considered \\
\hline 2.1 Quantification of fall incidence & $\begin{array}{l}\text { A Criteria for the definition of a fall were provided and applied } \\
\text { B Monthly returned fall diaries (i.e., fall calendar) } \\
\text { C Reminder calls by the examiners to avoid forgetting } \\
\text { reporting a fall [118-120] } \\
\text { D Objective fall rate measurement as using sensor-based instruments } \\
\text { (inertial sensors for daily life detection of falls) [121-124] }\end{array}$ \\
\hline 2.2 Intervention & $\begin{array}{l}\text { A Physical form of exercise intervention } \\
\text { B Group training under therapist supervision } \\
\text { C Exercise material guidance for home training (only relevant for } \\
\text { home training) } \\
\text { D Controlling home visits by therapists for home training (only } \\
\text { relevant for home training) } \\
\text { E Duration of the intervention } \geq 4 \text { weeks } \\
\text { F At least two times per week }[127,128] \\
\text { G Session duration } \geq 15 \text { min }[127,128] \\
\text { H Reporting compliance to the training (> 80\%) }\end{array}$ \\
\hline 3. Cofactors & $\begin{array}{l}\text { A positive point was assigned if the following aspects regarding the } \\
\text { participants were considered: } \\
\text { A Fall history in the previous } 6 \text { months or } 1 \text { year } \\
\text { B Activity profile during follow-up } \\
\text { C Influence of health status (diseases, medications) } \\
\text { D Influence of cognitive ability }\end{array}$ \\
\hline Statistical validity & Scoring \\
\hline 4. Statistical tests & A positive point was assigned if appropriate statistical tests were used \\
\hline 5. Power analysis & $\begin{array}{l}\text { A positive point was assigned if the sample size was calculated } \\
\text { based on an a priori power analysis }\end{array}$ \\
\hline External validity & Scoring \\
\hline 6. Eligibility of sample and variables & $\begin{array}{l}\text { A positive point was assigned if the intervention included as follows: } \\
1 \text { A representative sample } \\
2 \text { Appropriate report of the outcome variables }\end{array}$ \\
\hline 7. Description of the experimental protocol & $\begin{array}{l}\text { A positive point was assigned if the following criteria were } \\
\text { reported as follows: } \\
1 \text { Type of physical exercise intervention } \\
2 \text { Exercise descriptions and loading characteristics (e.g., intensity) } \\
3 \text { Intervention duration in weeks, training days per week, } \\
\text { and session duration }\end{array}$ \\
\hline 8. Description of the participant sample & $\begin{array}{l}\text { A positive point was assigned if the following criteria were } \\
\text { reported as follows: } \\
\text { A Age } \\
\text { B Sex } \\
\text { C Body height } \\
\text { D Body mass } \\
\text { E Activity level } \\
\text { F Health status (medication) } \\
\text { G Cognitive status } \\
\text { H Fall history }\end{array}$ \\
\hline
\end{tabular}

Numbers indicate full-point items while letters indicate subcategories of a one full-point item

Note that the internal validity increases with using better methods for quantification of fall incidence and implementation of intervention

(Fig. 1). Three studies [76, 82, 83] reported two different intervention groups while one study reported three different intervention groups [51]. Each intervention group of these studies was included separately as a single study data set, increasing the total number of included interventions to 31. Thus, in the manuscript and analysis, we will henceforth refer to the 31 included interventions instead of the included studies. 


\section{Description of the included studies}

The present systematic review included in total 31 interventions (participants in total $n=4739$ ), and their characteristics are summarized in Table 2. Twenty-four interventions reported both the fall rate and fall risk while three interventions investigated the fall risk only $[50,84,85]$ and four interventions reported only the fall rate $[83,86,87]$. The mean age of the included participants was $74.1 \pm 4.3$ years. In the 26 interventions that reported the sex distribution of their participants, in total, 3240 were females and 735 males. The mean follow-up duration of all interventions was $12.43 \pm 5.58$ months. The types of the implemented physical exercises were combined balance and strength training $(n=$ 16), balance-challenging mobility exercises in terms of trail-walking, complex obstacle negotiation exercises and multi-target stepping tasks $(n=6)$, Tai Chi $(n=4)$, balance training $(n=2)$, and strength training $(n=2)$. The type of physical exercises was not reported in one of the included interventions [85].

\section{Study quality assessment}

The results of the methodological quality assessment of the included studies are presented in Table 3 and showed an achieved mean total score of $73 \pm 11 \%$, i.e., internal validity $81 \pm 6 \%$, statistical validity $67 \pm 23 \%$, and external validity $71 \pm 14 \%$, indicating acceptable methodological quality for most studies with regard to the scope of the present meta-analysis. The risk of bias assessment indicated a low risk of bias within studies (Table 4). However, the judgment of the allocation concealment and blinding of the assessor to the data domains was in some studies unclear since respective information was not reported (Table 4). The participants of the control group of six studies were physically active and performed low-intensity exercising such as aerobics and stretching exercises or simple indoor walking or balance and strength exercises [76, 78, 79, $86,88,89]$, and in two studies, the intervention program was continued partially during the follow-up period [89, 90] (Table 3). Both cases might have biased the intervention effect. Egger's test for publication bias was not significant $(p=0.570)$, revealing low risk of publication bias.

\section{Meta-analysis of fall rate and fall risk}

The weighted average fall rate ratio (Fig. 2) of the included interventions was 0.68 (95\% confidence interval $0.58,0.80, p<0.001$, heterogeneity $\left.\left(I^{2}\right)=93 \%, n=28\right)$ and the fall risk ratio 0.78 (95\% confidence interval $0.68,0.89, p<0.001, I^{2}=71 \%, n=26$, Fig. 3). Accordingly, relative risk reduction was $32 \%$ for the fall events and $22 \%$ for the number of older adults who fell, respectively. Studies with interventions focusing on stability-challenging conditions and/or perturbation-based exercises (i.e., performance of complex balance exercises and training of dynamic stability control in the context of uneven/unstable underfoot conditions) $(n=6)$ showed lower weighted average fall rates and risks of 0.52 for both (i.e., $48 \%$ reduction) compared to the interventions that focused on strength and balance combined $(n=16)$ with a fall rate ratio of 0.69 (i.e., $31 \%$ reduction) and a fall risk ratio of 0.79 (i.e., $21 \%$ reduction). Studies of Tai Chi interventions $(n=4)$ showed a fall rate ratio of 0.79 (i.e., $21 \%$ reduction) and a fall risk ratio of 0.72 (i.e., $28 \%$ reduction). Studies of interventions focusing on strength alone $(n=2)$ demonstrated a fall rate ratio of 0.62 (i.e., $38 \%$ reduction) and a fall risk ratio of 0.87 (i.e., 13\% reduction). While studies of traditional balance intervention alone $(n=2)$ showed a fall rate ratio of 1.72 (i.e., no reduction) and a fall risk ratio of 1.92 (i.e., no reduction), balance functions were improved in these studies. However, a specific subgroup analysis on the type of the training was not conducted due to small subgroup sizes [70].

\section{Discussion}

The current systematic review and meta-analysis assessed the follow-up efficacy of physical exercise interventions of different types on fall occurrences during daily life in healthy older adults. Twenty-six studies (31 interventions), with a total number of 4739 participants, were included giving a weighted average fall rate ratio of 0.68 and risk ratio of 0.78 (intervention/control) with low risk of publication bias. Thus, the analysis provides valuable evidence that physical exercise interventions have the potential to reduce the fall incidence and number of older adult fallers in the post intervention follow-up period by 32 and $22 \%$, respectively.

In comparison, the training-induced reduction in fall incidence in the current meta-analysis was larger than those reported in the recent meta-analyses by Sherrington et al. [44], Gillespie et al. [40], Zhao et al. [49] and Sherrington et al. [59], i.e., 0.79 (21\% reduction), 0.71 ( $29 \%$ reduction), 0.85 ( $15 \%$ reduction), and 0.83 ( $17 \%$ reduction), respectively. Also, the reduction in the number fallers was greater than those reported by Guirguis-Blake et al. [69] (risk ratio $0.89,11 \%$ reduction), Tricco et al. [55] (0.83, 17\% reduction), and Gillespie et al. [40] (0.85, 15\% reduction). Additionally, the pronounced effect of exercise programs based on perturbation and stability training under challenging conditions on fall rate seen in the present meta-analysis (48\% reduction) was larger than that reported in Sherrington et al. [44] (39\%). To investigate the transfer and retention of training intervention effects on falls, the present meta-analysis included RCTs providing a followup time assessment after finishing the exercise intervention. However, the aforementioned meta-analyses [40, 44, $49,55,59,60,69]$ considered also studies in which the 


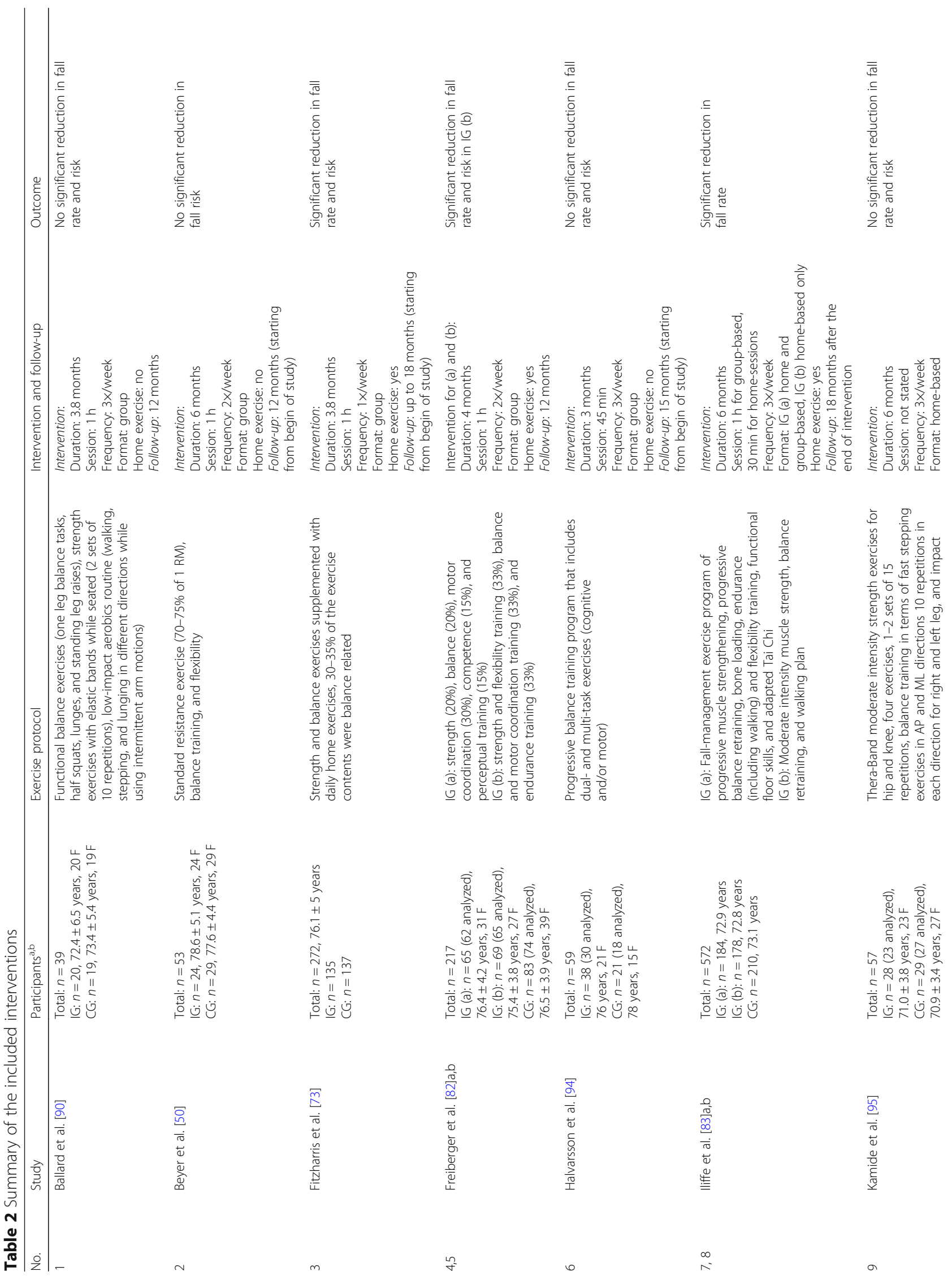




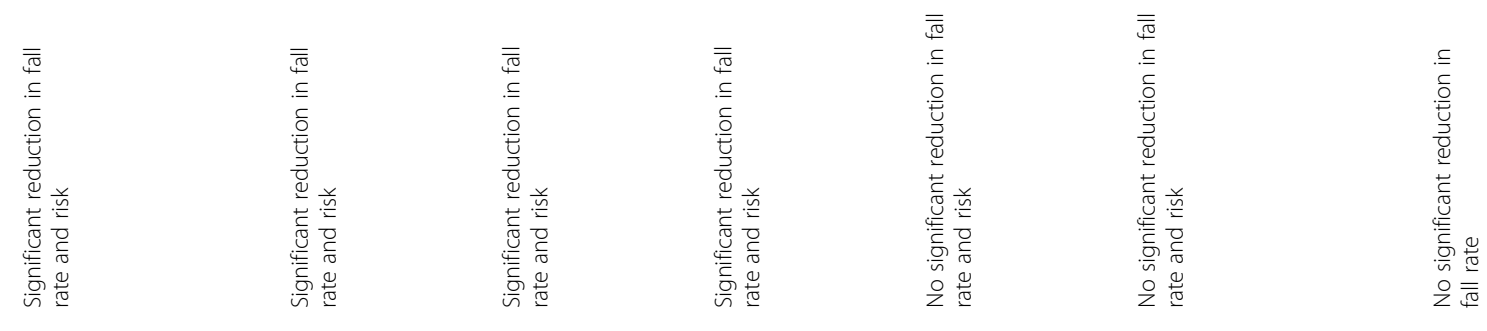

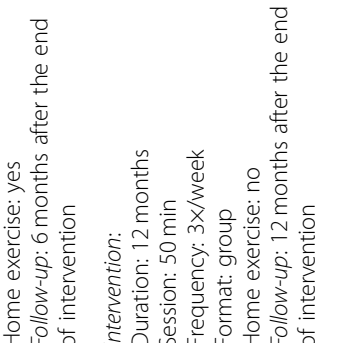

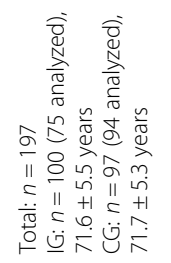

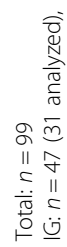




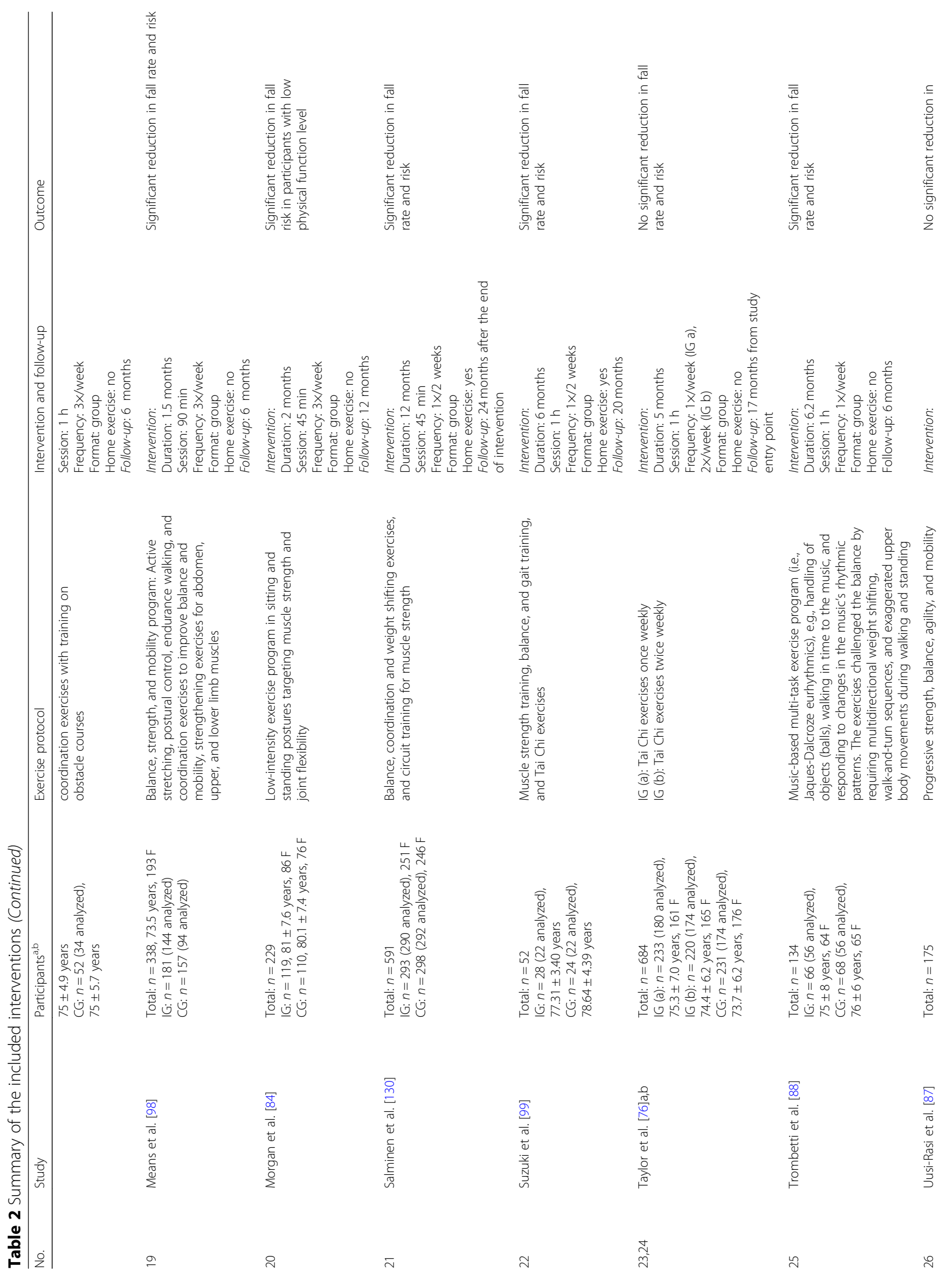




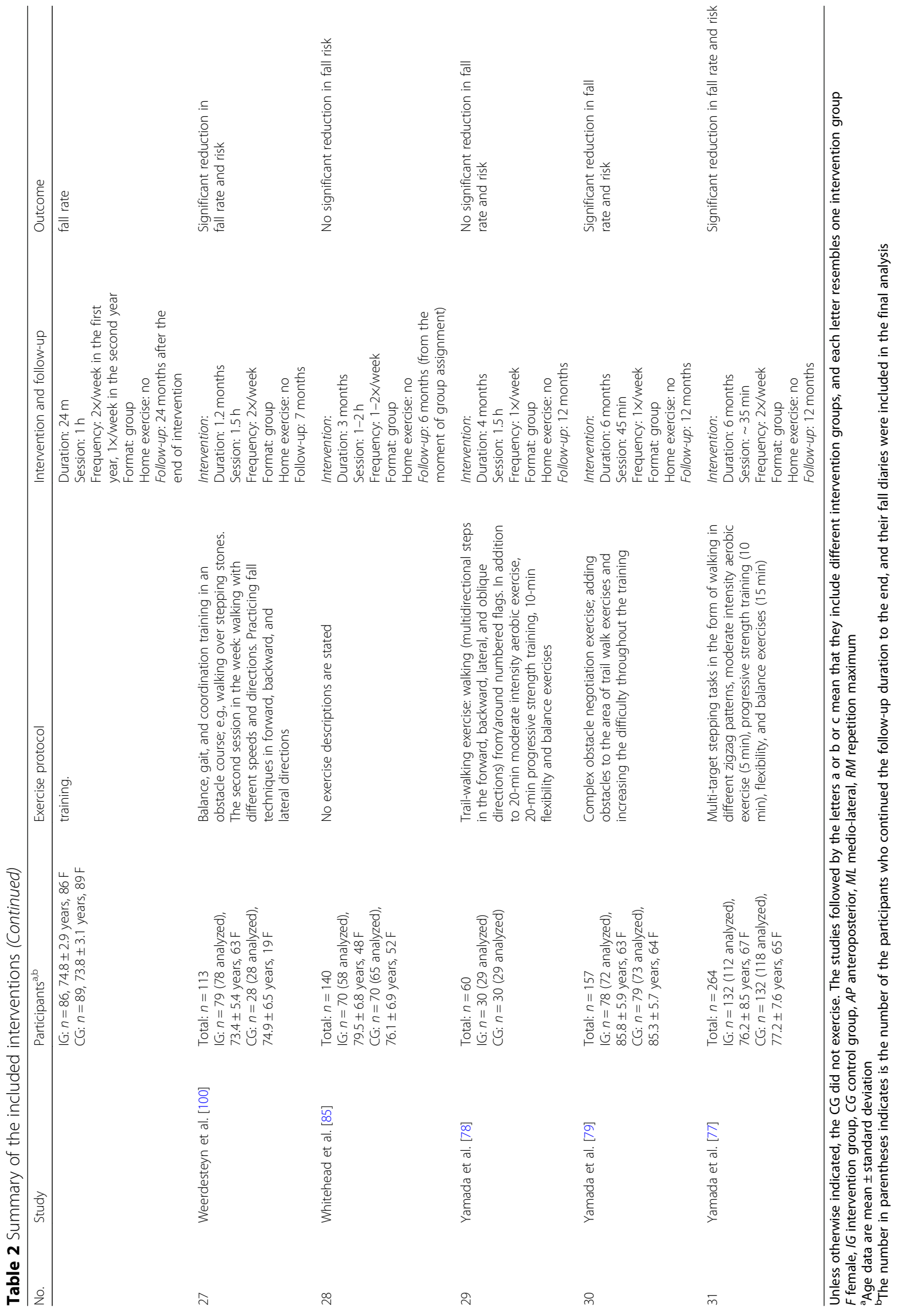




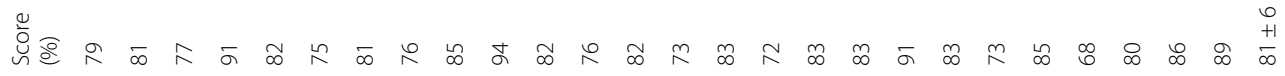
品

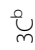
$\stackrel{\infty}{m}$ $\stackrel{\circ}{m}$

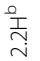

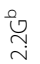

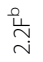

$\stackrel{\stackrel{ }{N}}{\sim}$

ิ

ֶֶ

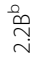

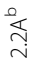

$\stackrel{\circ}{i}$

$\stackrel{\imath}{i}$

$\stackrel{\circ}{\sim}$

$\stackrel{8}{\mathrm{~N}}$

离

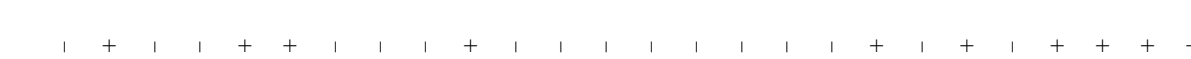

$+$

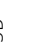

西

急

సু

רู

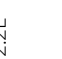

(1)

.

సิ

ㄱ.

i

$\frac{i}{i}$

i

i 


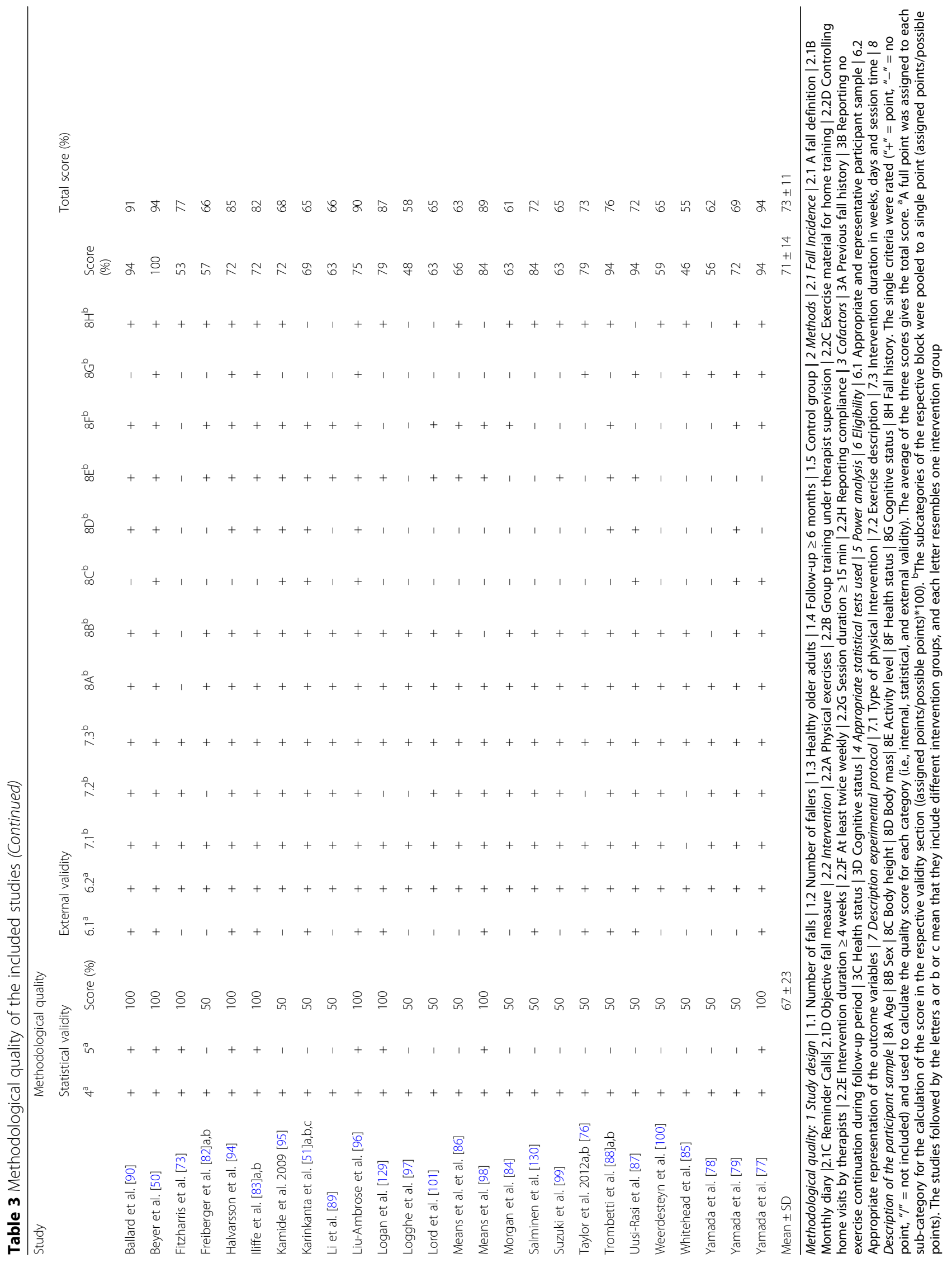


Table 4 Risk of bias assessment of the included studies according to Cochrane risk of bias assessment tool [75]

\begin{tabular}{|c|c|c|c|c|c|c|c|}
\hline \multirow[t]{2}{*}{ Study } & \multicolumn{7}{|l|}{ Risk of bias } \\
\hline & Sequence & Allocation & Blinding & Outcome & Report & Other & Notes \\
\hline Ballard et al. [90] & Yes & Unclear & Unclear & Yes & Yes & Yes & $\begin{array}{l}\text { Control group attended the exercise } \\
\text { program in the first } 2 \text { weeks as a motivation. } \\
\text { Examiners were not blinded to groups. } \\
\text { Fall diaries were completed at } 1 \text {-year follow-up, } \\
\text { not on a monthly basis. }\end{array}$ \\
\hline Beyer et al. [50] & Yes & Yes & Unclear & Yes & Yes & Yes & $\begin{array}{l}\text { The follow-up started from the point of } \\
\text { group assignment. }\end{array}$ \\
\hline Fitzharris et al. [73] & Yes & Unclear & Unclear & Yes & Unclear & Unclear & \\
\hline Freiberger et al. [82]a,b & Yes & Yes & Yes & Yes & Yes & Unclear & \\
\hline Halvarsson et al. [94] & Yes & Yes & Unclear & Yes & Yes & Yes & $\begin{array}{l}\text { Seventeen out of the } 59 \text { total had neurological } \\
\text { and cardiovascular diseases. } \\
\text { Fall frequency was assessed retrospectively at } \\
\text { the end of the follow-up, not on a } \\
\text { monthly basis calendars. }\end{array}$ \\
\hline lliffe et al. [83]a,b & Yes & Unclear & Yes & Yes & Yes & Yes & \\
\hline Kamide et al. [95] & Yes & Yes & Yes & Yes & Yes & Yes & \\
\hline Karinkanta et al. [51]a,b,c & Yes & Unclear & Unclear & Yes & Yes & Unclear & \\
\hline Li et al. [89] & Yes & Unclear & Unclear & Yes & Yes & Unclear & \\
\hline Liu-Ambrose et al. [96] & Yes & Yes & Yes & Yes & Yes & Unclear & \\
\hline Logan et al. [129] & Yes & Yes & Yes & Yes & Yes & Yes & \\
\hline Logghe et al. [97] & Yes & Unclear & Yes & Yes & Yes & Yes & \\
\hline Lord et al. [101] & Yes & Unclear & Unclear & Yes & Yes & Unclear & \\
\hline Means et al. [86] & Yes & Unclear & Unclear & Yes & Yes & Yes & $\begin{array}{l}\text { Control group attended balance program without } \\
\text { training on obstacle course. }\end{array}$ \\
\hline Means et al. [98] & Yes & Yes & No & Yes & Yes & Yes & \\
\hline Morgan et al. [84] & Yes & Unclear & Unclear & Yes & Yes & Unclear & \\
\hline Salminen et al. [130] & Yes & Yes & Yes & Yes & Yes & Yes & \\
\hline Suzuki et al. [99] & Yes & Unclear & Yes & Yes & Yes & Yes & \\
\hline Taylor et al. [76]a,b & Yes & Yes & Yes & Yes & Yes & Unclear & $\begin{array}{l}\text { The follow-up duration started from the entry point } \\
\text { in the study to the final assessment point (i.e., the } \\
\text { intervention duration is included in } \\
\text { the follow-up period). }\end{array}$ \\
\hline Trombetti et al. [88] & Yes & Yes & Yes & Yes & Yes & Unclear & $\begin{array}{l}\text { The control group was a delayed intervention control } \\
\text { group that started the same implemented } \\
\text { intervention during the } 6 \text { months of follow-up. }\end{array}$ \\
\hline Uusi-Rasi et al. [87] & Yes & Unclear & Yes & Yes & Unclear & Unclear & \\
\hline Weerdesteyn et al. [100] & Yes & Unclear & Unclear & Yes & Yes & Unclear & $\begin{array}{l}\text { Half of the intervention group was not randomly assigned. } \\
\text { The follow-up started from the point of group assignment. }\end{array}$ \\
\hline Whitehead et al. [85] & Yes & Yes & Yes & Yes & Yes & Unclear & The follow-up started from the point of group assignment. \\
\hline Yamada et al. [78] & Yes & Yes & Yes & Yes & Yes & Unclear & \\
\hline Yamada et al. [79] & Yes & Yes & Unclear & Yes & Yes & Unclear & \\
\hline Yamada et al. [77] & Yes & Yes & Yes & Yes & Yes & Unclear & \\
\hline
\end{tabular}

Sequence Was the allocation sequence adequately generated? Allocation Was allocation adequately concealed? Blinding Was knowledge of the allocated intervention adequately prevented during the study? Outcome Were incomplete outcome data adequately addressed? Report Are reports of the study free of suggestion of selective outcome reporting? Other Was the study apparently free of other problems that could put it at high risk of bias? The studies followed by the letters a or b or c mean that they include different intervention groups, and each letter resembles one intervention group

intervention time was part of the follow-up time (follow-up starts at intervention onset). From a physiological perspective, it can be expected that intervention benefits occur after a certain volume of training (number of sessions over time) [91-93] and might become functionally relevant (i.e., reduce falls) even later and, further, that biological responses progress over the time-course of intervention. Therefore, given that the period of intervention in this 


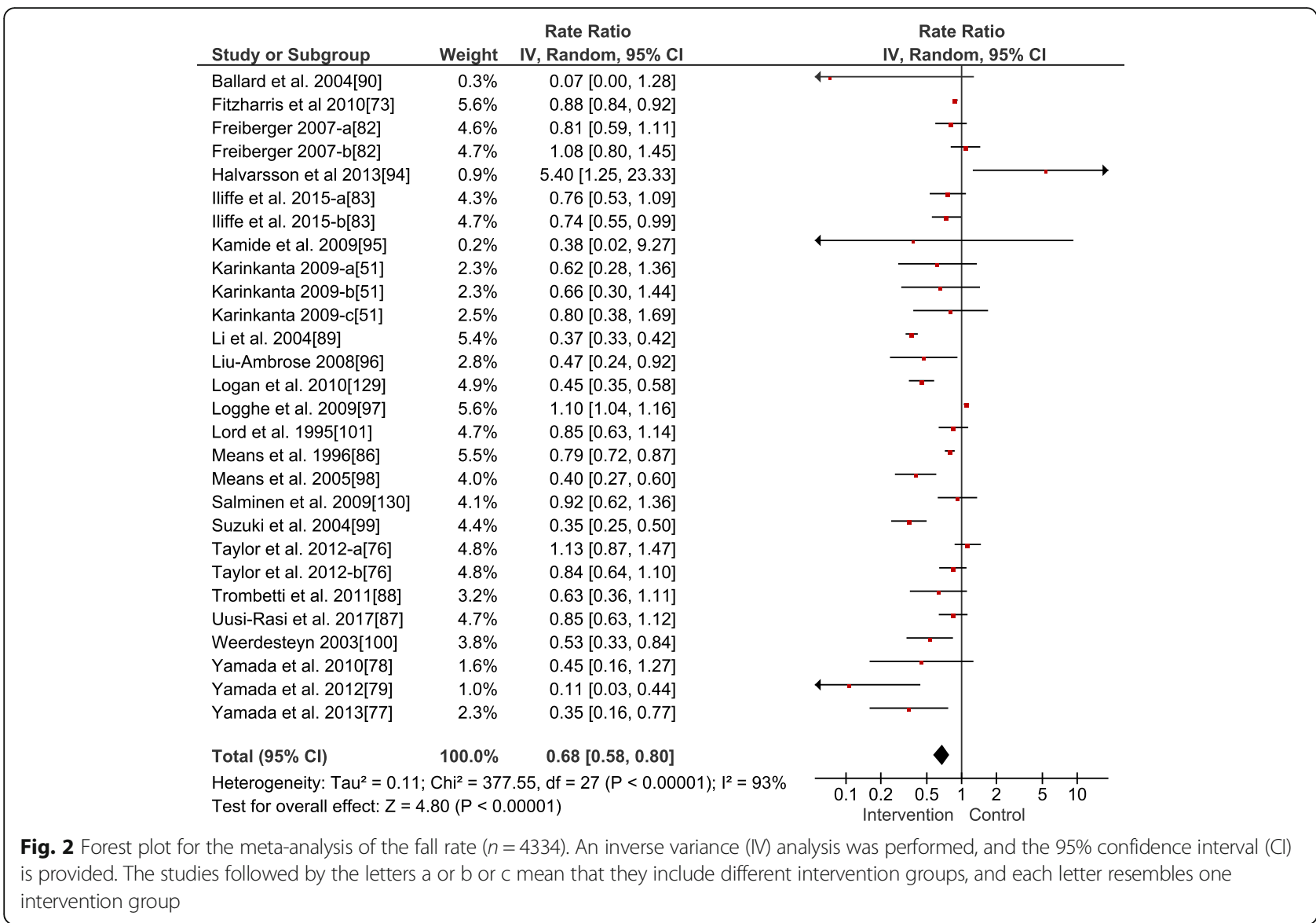

analysis may include a time when training effects have not (yet) become effective, and that this period might be a significant portion of the assessed overall follow-up time (e.g., in the present data set the average intervention time of 5.6 months would be almost one third of the overall follow-up time of 18.0 months), this might explain the lower observed effects on fall rate ratio and risk ratio reported in the previously published analyses compared with the current meta-analysis. Furthermore, for the same reason (follow-up time vs. follow-up time including intervention time), fewer and different studies were included in the present analysis compared to the previous meta-analysis (i.e. 10 [83, 88, 94-101] of the 26 studies included in the current meta-analysis were included in the 88 studies meta-analyzed by Sherrington et al. [44]).

The findings of the current analysis indicate that the reduction in the number of older persons who fell and the number of their fall events during daily life can be largely retained by about one third when participating in physical exercise interventions. Therefore, physical exercise interventions, being cheap and easy to implement (e.g., group settings in senior centers, home-based exercising), seem to be generally effective treatments of the age-related increase in fall risk. The implementation of such interventions may thus reduce fall-related injury clinical care burdens not only the individual but also the social health care systems.

The improvements in the general outcomes fall risk and number of fallers are likely the consequence of improvements in relevant intrinsic age-related fall risk factors. For example, balance and strength were seen to be improved after such intervention programs [50, 76, 88, 89, 94, 98, $100,101]$ in association with improvements in more general physical functions (e.g., timed up and go test performance, functional reaching, and sit to stand time) [50, 77, $82,101]$ and gait functional performance (e.g., gait velocity, stride length, and gait variability performance) [77, 88, 89, 100]. Accordingly, carryover effects were reported since the improvement in the gait and balance performance was retained after the cessation of the intervention program and during the follow-up duration [50, 88, 94]. However, improvements in these capacities and related functions might decrease or normalize over time when training is not continued, and persistent training is therefore needed to maintain the exercise-related benefits on fall risk factors.

In our analysis, the included studies applied a broad spectrum of physical exercises (balance, strength, mobility, 


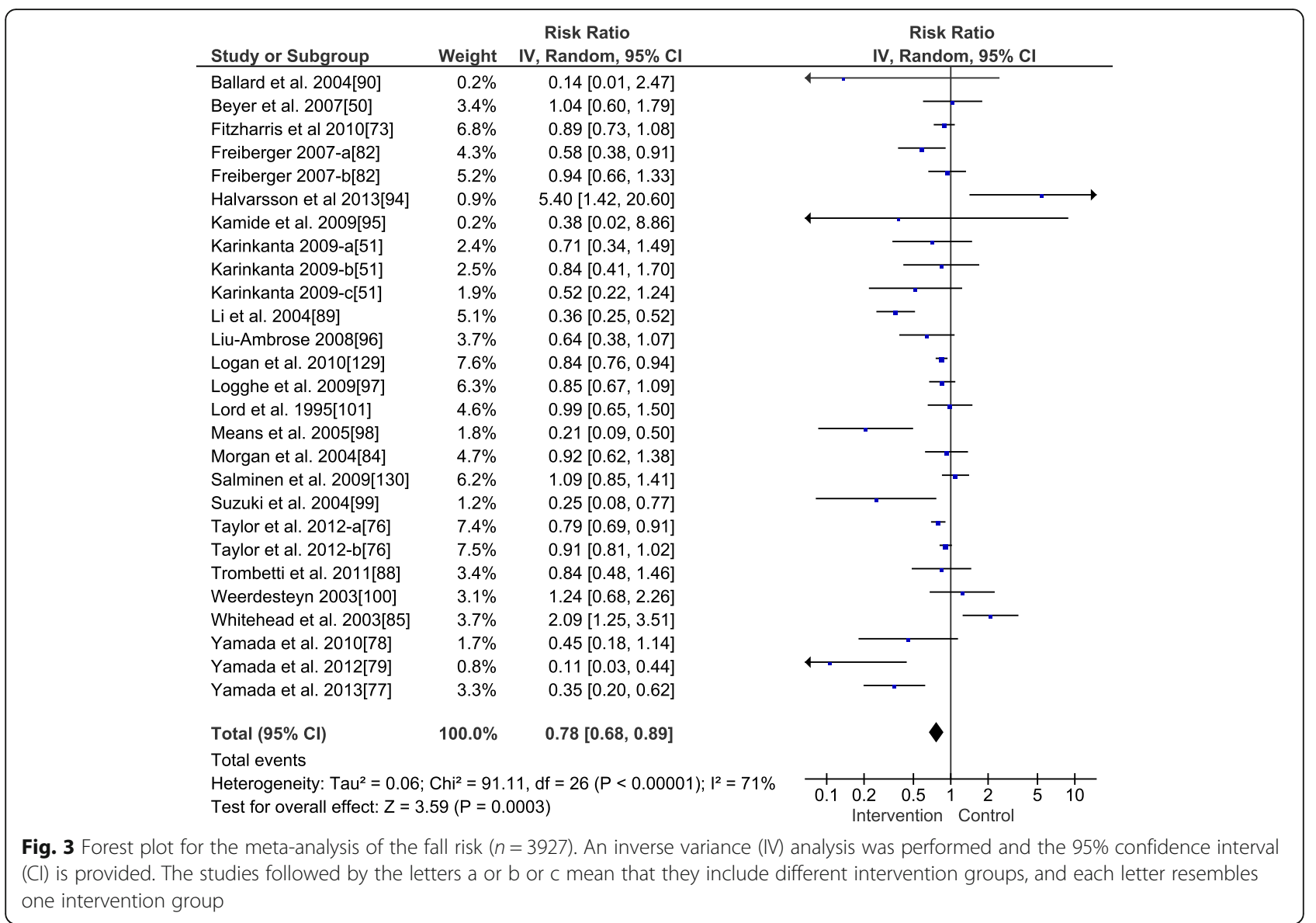

combined balance and strength, Tai Chi, and balancechallenging mobility exercises), and except in a few cases, all these interventions decreased the risk of falling. With respect to efficacy, the interventions using stability-challenging conditions in their training and/or perturbation-based exercises (i.e., complex balance exercises and training of dynamic stability control in the context of uneven/unstable underfoot conditions) showed greater effects on fall rate and fall risk (i.e., $48 \%$ reduction for both) compared to interventions that focused on Tai Chi (21 and 28\% reduction) and strength and balance combined (31 and $21 \%$ reduction). This may indicate a pronounced effectiveness of training interventions using stability-challenging conditions. However, it is important to note that this comparison was based on a very limited data set $(n=6, n=4$, and $n=$ 16) and accordingly could not be statistically verified. Furthermore, not all of those studies were of appropriate methodological quality (Tables 3 and 4). Therefore, further systematic research is warranted to enable more definitive conclusions to be drawn. The indication of superior effects of perturbation-based training is nevertheless supported by the evidence from previous meta-analyses $[44,59,60]$ and by current experimental studies that showed remarkable reductions in the annual self-reported fall risk of $43-50 \%$ following a single session of repeated unexpected slip exposures during walking $[62,102,103]$. Indeed, the degree of retention and transfer seem to depend on the intensity of the experienced perturbation, with greater effects seen with greater postural threats [104-107]. It might be argued that training balance control mechanisms using challenging conditions might improve the feedforward and feedback control of stability $[68,108-112]$ in an intensity-related manner, improving recovery performance following subsequent exposure to sudden perturbations during daily life situations. Moreover, it has recently been shown that specific strenuous balance exercises on unstable surfaces (challenging postural conditions) improved both recovery performance and muscle strength [113], thus increasing the efficiency of the intervention. The authors of the latter study suggested that the instability might increase muscle activation during exercising, which might stimulate strength gains alongside balance control mechanism improvements [113-115]. In this way, both deficient factors (balance and strength) could be trained at the same time. Therefore, including challenging balance conditions and perturbations may be a promising approach in fall prevention interventions. 
The two studies which targeted balance alone [51, 53] showed no reductions in either fall rate (1.72) or risk ratio (1.92), although balance functions were improved in these studies. As reported by the authors [53], this was likely due to the training-related increases in activity level and self-confidence and a decreased fear of falling. Therefore, their exposure to balance-threatening events may have been increased. Again, due to the low number assigned to the different training components (stabilitychallenging perturbation training $n=6$, combined strength and balance training $n=16$, Tai Chi $n=4$, traditional balance training $n=2$, strength training $n=2$ ), it was not possible to investigate any dose-response relationships in the current meta-analysis. However, it has been shown that intervention programs based on challenging balance exercises with a frequency of two and/ or $3 \mathrm{~h}$ or more per week over a time period of 6 months have large effects on fall rate during and following the intervention program $[44,59,60]$.

The total methodological quality score in the present meta-analysis ranged from 55 to $94 \%$, with a mean of $73 \%$, indicating moderate to high methodological quality of the included studies. However, several aspects were not present in every study. Fall rate was not investigated in three of the included interventions [50, 84, 85] while fall risk was not examined in four interventions [83, 86, 87]. Reporting fall incidence without reporting the number of single and multiple fallers (i.e., number of falls per patient) can bias the study results because certain participants may fall more often than others [74, 116]. Furthermore, an operational definition of a fall should be provided for seniors and health care providers to facilitate adequate quantification of falls [117]. The criteria of fall definition were not provided in nine of the included interventions [51, 83, 84, 90, 97, 99]. Furthermore, in order to reduce inaccuracies caused by memory lapses, it is recommended that fall diaries be completed on a daily basis and returned monthly rather than at the end of the follow-up period [118-120]. A validated instrument for detecting falls, e.g., using sensors [121-124] might reduce the aforementioned issues of self-reports. However, sensor-based wearable fall detection devices have been shown to be prone to errors such as false alarms and are not yet sufficiently precise and valid to be used in a scientific context $[125,126]$. None of the included studies used such a methodology for the quantification of falls. The description of the experimental protocol and participants was appropriate in most of the included interventions, resulting in a moderate to high mean external validity score of $69 \%$, although detailed information on the loading characteristics and detailed description of the exercise program were mostly missing. The risk of bias assessment indicated low risk for all interventions.
In the present systematic review and meta-analysis, only healthy older adults were included; thus, a generalization of the findings to older adults with different characteristics (e.g., frailty, diseases such as Parkinson disease) warrants confirmation.

\section{Conclusion}

In conclusion, the present systematic review and metaanalysis provides evidence that physical exercise interventions significantly reduce fall rate and fall risk in healthy older adults during post intervention follow-up. This indicates that older adults benefit from physical exercise that targets age-related strength deficits and impaired stability control. However, detailed information on effective doseresponse relationships remains sparse. Based on our results and other evidence, a possible recommendation could be to include challenging balance conditions and perturbations in exercise interventions to reduce the fall risk in older adults.

\section{Additional file}

Additional file 1: Electronic bibliographic databases that were searched and applied respective search syntax. (DOCX 13 kb)

\section{Abbreviations \\ $P^{2}$ : Heterogeneity; MeSH: Medical Subject Headings}

\section{Acknowledgements}

We acknowledge support by the German Research Foundation (DFG) and the Open Access Publication Fund of Humboldt-Universität zu Berlin.

\section{Funding}

Azza Hamed was supported by a scholarship from the German Academic Exchange Service (DAAD). The DAAD was not involved in the design of the study and collection, analysis, and interpretation of data and in writing the manuscript. No other sources of funding were used to assist in the preparation of this article.

\section{Availability of data and materials}

Data sharing is not applicable to this article as no datasets were generated or analyzed during the current study.

\section{Authors' contributions}

$\mathrm{AH}$ conceived, designed, and executed the systematic review and metaanalysis; contacted authors; interpreted the findings; and drafted and revised the article. SB conceived, designed, and executed the systematic review and meta-analysis; interpreted the findings; and drafted and revised the article. FM executed the systematic review, interpreted the findings, and drafted and revised the article. AA conceived and designed the systematic review and meta-analysis, interpreted the findings, and drafted and revised the article. All authors read and approved the final manuscript.

Ethics approval and consent to participate Not applicable

\section{Consent for publication \\ Not applicable}

\section{Competing interests}

The authors, Azza Hamed, Sebastian Bohm, Falk Mersmann, and Adamantios Arampatzis, declare that they have no competing interests. 


\section{Publisher's Note}

Springer Nature remains neutral with regard to jurisdictional claims in published maps and institutional affiliations.

\section{Author details}

'Department of Training and Movement Sciences, Humboldt-Universität zu Berlin, Philippstr. 13, Haus 11, 10115 Berlin, Germany. ${ }^{2}$ Berlin School of Movement Science, Berlin, Germany. ${ }^{3}$ Department of Biomechanics, Faculty of Physical Therapy, Cairo University, Cairo, Egypt.

\section{Received: 16 May 2018 Accepted: 9 November 2018} Published online: 13 December 2018

\section{References}

1. Roberts S, Colombier P, Sowman A, Mennan C, Rölfing JHD, Guicheux J. Ageing in the musculoskeletal system: cellular function and dysfunction throughout life. Acta Orthop. 2016;87:15-25.

2. Vandervoort AA. Aging of the human neuromuscular system. Muscle Nerve. 2002:25:17-25

3. Horak FB, Shupert CL, Mirka A. Components of postural dyscontrol in the elderly: a review. Neurobiol Aging. 1989;10:727-38.

4. Prince F, Corriveau H, Hébert R, Winter DA. Gait in the elderly. Gait Posture. 1997:5:128-35

5. Tinetti ME, Baker DI, Garrett PA, Gottschalk M, Koch ML, Horwitz RI. Yale FICSIT: risk factor abatement strategy for fall prevention. J Am Geriatr Soc. 1993;41:315-20

6. Huang HC, Liu CY, Huang YT, Kernohan WG. Community-based interventions to reduce falls among older adults in Taiwan - long time follow-up randomised controlled study. J Clin Nurs. 2010;19:959-68.

7. Gill T, Taylor AW, Pengelly A. A population-based survey of factors relating to the prevalence of falls in older people. Gerontology. 2005;51:340-5.

8. O'Loughlin JL, Robitaille Y, Boivin J-F, Suissa S. Incidence of and risk factors for falls and injurious falls among the community-dwelling elderly. Am J Epidemiol. 1993;137:342-54.

9. Blake AJ, Morgan K, Bendall MJ, Dallosso H, Ebrahim SBJ, Arie THD. Falls by elderly people at home: prevalence and associated factors. Age Ageing. 1988;17:365-72.

10. Tinetti ME, Speechley M, Ginter SF. Risk factors for falls among elderly persons living in the community. N Engl J Med. 1988:319:1701-7.

11. Robinovitch SN, Feldman F, Yang Y, Schonnop R, Leung PM, Sarraf T. Video capture of the circumstances of falls in elderly people residing in long-term care: an observational study. Lancet. 2013;381:47-54.

12. Nachreiner NM, Findorff MJ, Wyman JF, McCarthy TC. Circumstances and consequences of falls in community-dwelling older women. J Women's Health. 2007;16:1437-46

13. Salvà A, Bolíbar I, Pera G, Arias C. Incidence and consequences of falls among elderly people living in the community. Med Clin (Barc). 2004; 122:172-6.

14. Tucker MG, Kavanagh JJ, Morrison S, Barrett RS. Voluntary sway and rapid orthogonal transitions of voluntary sway in young adults, and low and high fall-risk older adults. Clin Biomech. 2009;24:597-605.

15. Talbot LA, Musiol RJ, Witham EK, Metter EJ. Falls in young, middle-aged and older community dwelling adults: perceived cause, environmental factors and injury. BMC Public Health. 2005:5:86-94.

16. Chen H-C, Schultz AB, Ashton-Miller JA, Giordani B, Alexander NB, Guire KE. Stepping over obstacles: dividing attention impairs performance of old more than young adults. J Gerontol Ser A Biol Sci Med Sci. 1996; 51A:M116-22.

17. Luchies CW, Alexander NB, Schultz AB, Ashton-Miller J. Stepping responses of young and old adults to postural disturbances: kinematics. J Am Geriatr Soc. 1994:42:506-12.

18. Baker SP, Harvey AH. Fall injuries in the elderly. Clin Geriatr Med. 1985 1:501-12.

19. Kannus $P$, Sievänen $H$, Palvanen $M$, Järvinen $T$, Parkkari J. Prevention of falls and consequent injuries in elderly people. Lancet. 2005:366:1885-93.

20. Rosenberg $\mathrm{H}$. Sarcopenia: origins and clinical relevance. Clin Geriatr Med. 2011;27:337-9.

21. Arampatzis A, Karamanidis K, Mademli L. Deficits in the way to achieve balance related to mechanisms of dynamic stability control in the elderly. J Biomech. 2008;41:1754-61.
22. Karamanidis K, Arampatzis A, Mademli L. Age-related deficit in dynamic stability control after forward falls is affected by muscle strength and tendon stiffness. J Electromyogr Kinesiol. 2008;18:980-9.

23. Horlings CGC, van Engelen BGM, Allum JHJ, Bloem BR. A weak balance: the contribution of muscle weakness to postural instability and falls. Nat Clin Pract Neurol. 2008:4:504-15.

24. Pijnappels $M$, Reeves ND, Maganaris CN, van Dieën JH. Tripping without falling: lower limb strength, a limitation for balance recovery and a target for training in the elderly. J Electromyogr Kinesiol. 2008;18:188-96.

25. Cronin NJ, Barrett RS, Lichtwark G, Mills PM, Carty CP. Decreased lower limb muscle recruitment contributes to the inability of older adults to recover with a single step following a forward loss of balance. J Electromyogr Kinesiol. 2013:23:1139-44.

26. Scaglioni G, Narici MV, Martin A. Neural activation during submaximal contractions seems more reflective of neuromuscular ageing than maximal voluntary activation. Front Aging Neurosci. 2016;8:19.

27. Mademli $\mathrm{L}$, Arampatzis $\mathrm{A}$. Effect of voluntary activation on age-related muscle fatigue resistance. J Biomech. 2008;41:1229-35.

28. Morse Cl, Thom JM, Davis MG, Fox KR, Birch KM, Narici MV. Reduced plantarflexor specific torque in the elderly is associated with a lower activation capacity. Eur J Appl Physiol. 2004;92:219-26.

29. Stevens JE, Stackhouse SK, Binder-Macleod SA, Snyder-Mackler L. Are voluntary muscle activation deficits in older adults meaningful? Muscle Nerve. 2003:27:99-101.

30. Pousson M, Lepers R, Van Hoecke J. Changes in isokinetic torque and muscular activity of elbow flexors muscles with age. Exp Gerontol. 2001;36:1687-98.

31. Narici MV, Maffulli N, Maganaris CN. Ageing of human muscles and tendons. Disabil Rehabil. 2008:30:1548-54.

32. Jubrias SA, Odderson IR, Esselman PC, Conley KE. Decline in isokinetic force with age: muscle cross-sectional area and specific force. Pflugers Arch Eur J Physiol. 1997:434:246-53

33. Narici MV, Maffulli N. Sarcopenia: characteristics, mechanisms and functional significance. Br Med Bull. 2010;95:139-59.

34. Narici MV, Maganaris CN, Reeves ND, Capodaglio P. Effect of aging on human muscle architecture. J Appl Physiol. 2003;95:2229-34.

35. Han L, Yang F. Strength or power, which is more important to prevent sliprelated falls? Hum Mov Sci. 2015;44:192-200.

36. Skelton DA, Greig CA, Davies JM, Young A. Strength, power and related functional ability of healthy people aged 65-89 years. Age Ageing. 1994:23:371-7.

37. Raj IS, Bird SR, Shield AJ. Aging and the force-velocity relationship of muscles. Exp Gerontol. 2010:45:81-90.

38. Hof AL. The equations of motion for a standing human reveal three mechanisms for balance. J Biomech. 2007:40:451-7.

39. Moyer VA. Prevention of falls in community-dwelling older adults: U.S preventive services task force recommendation statement. Ann Intern Med. 2012:157:197.

40. Gillespie LD, Robertson MC, Gillespie WJ, Sherrington C, Gates S, Clemson LM, et al. Interventions for preventing falls in older people living in the community. Cochrane Database Syst Rev. 2012;9:CD007146.

41. Panel on Prevention of falls in older persons, American Geriatrics Society and British Geriatrics Society. Summary of the updated American Geriatrics Society/British Geriatrics Society clinical practice guideline for prevention of falls in older persons. J Am Geriatr Soc. 2011;59:148-57.

42. Kim $\mathrm{Kl}$, Jung $\mathrm{H}-\mathrm{K}$, Kim $\mathrm{CO}$, Kim S-K, Cho $\mathrm{H}-\mathrm{H}$, Kim DY. Evidencebased guidelines for fall prevention in Korea. Korean J Intern Med. 2017:32:199-210.

43. National Institute for Health and Care Excellence. In: Recommendations; preventing falls in elderly people. 2013. https://www.nice.org.uk/guidance/ cg161/chapter/1-Recommendations\#preventing-falls-in-older-people. Accessed 19 Oct 2018

44. Sherrington C, Michaleff ZA, Fairhall N, Paul SS, Tiedemann A, Whitney J, et al. Exercise to prevent falls in older adults: an updated systematic review and meta-analysis. Br J Sports Med. 2017:51:1750-8.

45. McCrum C, Gerards MHG, Karamanidis K, Zijlstra W, Meijer K. A systematic review of gait perturbation paradigms for improving reactive stepping responses and falls risk among healthy older adults. Eur Rev Aging Phys Act. 2017;14:3.

46. Li F, Harmer P, Fisher KJ, McAuley E, Chaumeton N, Eckstrom E. Tai Chi and fall reductions in older adults: a randomized controlled trial. J Gerontol - Ser A Biol Sci Med Sci. 2005;60:187-94. 
47. Taggart HM. Effects of tai chi exercise on balance, functional mobility, and fear of falling among older women. Appl Nurs Res. 2002;15:235-42.

48. García-Molina R, Ruíz-Grao MC, Noguerón-García A, Martínez-Reig M, Esbrí-Víctor $\mathrm{M}$, Izquierdo $\mathrm{M}$, et al. Benefits of a multicomponent falls unit-based exercise program in older adults with falls in real life. Exp Gerontol. 2018;110:79-85.

49. Zhao $R$, Feng $F$, Wang $X$. Exercise interventions and prevention of fallrelated fractures in older people: a meta-analysis of randomized controlled trials. Int J Epidemiol. 2017;46:149-61.

50. Beyer N, Simonsen L, Bülow J, Lorenzen T, Jensen DV, Larsen L, et al. Old women with a recent fall history show improved muscle strength and function sustained for six months after finishing training. Aging Clin Exp Res. 2007:19:300-9.

51. Karinkanta S, Heinonen A, Sievänen H, Uusi-Rasi K, Fogelholm M, Kannus P. Maintenance of exercise-induced benefits in physical functioning and bone among elderly women. Osteoporos Int. 2009;20:665-74.

52. Iwamoto J, Suzuki H, Tanaka K, Kumakubo T, Hirabayashi H, Miyazaki Y, et al. Preventative effect of exercise against falls in the elderly: a randomized controlled trial. Osteoporos Int. 2009;20:1233-40.

53. Halvarsson A, Olsson E, Farén E, Pettersson A, Stahle A. Effects of new, individually adjusted, progressive balance group training for elderly people with fear of falling and tend to fall: a randomized controlled trial. Clin Rehabil. 2011;25:1021-31.

54. Thomas S, Mackintosh S, Halbert J. Does the "Otago exercise programme" reduce mortality and falls in older adults?: a systematic review and metaanalysis. Age Ageing. 2010;39:681-7.

55. Tricco AC, Thomas SM, Veroniki AA, Hamid JS, Cogo E, Strifler L, et al. Comparisons of interventions for preventing falls in older adults. JAMA. 2017;318:1687-99.

56. El-Khoury F, Cassou B, Charles M-A, Dargent-Molina P. The effect of fall prevention exercise programmes on fall induced injuries in community dwelling older adults: systematic review and meta-analysis of randomised controlled trials. BMJ. 2013;347:f6234-47.

57. El-Khoury F, Cassou B, Latouche A, Aegerter P, Charles M-A, Dargent-Molina $P$. Effectiveness of two year balance training programme on prevention of fall induced injuries in at risk women aged 75-85 living in community: Ossébo randomised controlled trial. BMJ. 2015;351:h3830.

58. Kim H, Yoshida H, Suzuki T. Falls and fractures in participants and excluded non-participants of a fall prevention exercise program for elderly women with a history of falls: 1-year follow-up study. Geriatr Gerontol Int. 2014;14:285-92.

59. Sherrington C, Whitney JC, Lord SR, Herbert RD, Cumming RG, Close JCT. Effective exercise for the prevention of falls: a systematic review and metaanalysis. J Am Geriatr Soc. 2008;56:2234-43.

60. Sherrington C, Tiedemann A, Fairhall N, Close JCT, Lord SR. Exercise to prevent falls in older adults: an updated meta-analysis and best practice recommendations. N S W Public Health Bull. 2011;22:78-83.

61. Bohm S, Mademli L, Mersmann F, Arampatzis A. Predictive and reactive locomotor adaptability in healthy elderly: a systematic review and metaanalysis. Sport Med. 2015:45:1759-77.

62. Pai YC, Yang F, Bhatt T, Wang E. Learning from laboratory-induced falling: long-term motor retention among older adults. Age (Dordr). 2014;36:9640.

63. Bierbaum S, Peper A, Karamanidis K, Arampatzis A. Adaptive feedback potential in dynamic stability during disturbed walking in the elderly. J Biomech. 2011:44:1921-6.

64. Bhatt T. Long-term retention of gait stability improvements. J Neurophysiol. 2005:94:1971-9.

65. Bierbaum S, Peper A, Arampatzis A. Exercise of mechanisms of dynamic stability improves the stability state after an unexpected gait perturbation in elderly. Age. 2013;35:1905-15.

66. Melnyk JA, Rogers MA, Hurley BF. Effects of strength training and detraining on regional muscle in young and older men and women. Eur J Appl Physiol. 2009;105:929-38.

67. Morse Cl, Thom JM, Mian OS, Muirhead A, Birch KM, Narici MV. Muscle strength, volume and activation following 12-month resistance training in 70-year-old males. Eur J Appl Physiol. 2005;95:197-204.

68. Wang TY, Bhatt T, Yang F, Pai YC. Generalization of motor adaptation to repeated-slip perturbation across tasks. Neuroscience. 2011;180:85-95.

69. Guirguis-Blake JM, Michael YL, Perdue LA, Coppola EL, Beil TL. Interventions to prevent falls in older adults: updated evidence report and systematic review for the US preventive services task force. JAMA. 2018;319:1705-16.
70. Higgins JP, Green S. Cochrane handbook for systematic reviews of interventions: Cochrane book series. Cochrane Handb Syst Rev Interv Cochrane B Ser. 2010;2008:1-649.

71. Egger M, Davey Smith G, Schneider M, Minder C. Bias in meta-analysis detected by a simple, graphical test. BMJ. 1997;315:629-34.

72. Day L. Randomised factorial trial of falls prevention among older people living in their own homes. BMJ. 2002;325:128.

73. Fitzharris MP, Day L, Lord SR, Gordon I, Fildes B. The Whitehorse NoFalls trial: effects on fall rates and injurious fall rates. Age Ageing. 2010;39:728-33.

74. Gaebler S. Predicting which patient will fall again and again. J Adv Nurs. 1993;18:1895-902.

75. Higgins JP, Green S. Cochrane handbook for systematic reviews of interventions: Cochrane book series. In: Higgins JP, Green S, editors. Analysing data and undertaking meta-analyses. Chichester: Wiley; 2008. p. 243-96.

76. Taylor D, Hale L, Schluter P, Waters DL, Binns EE, McCracken H, et al. Effectiveness of tai chi as a community-based falls prevention intervention: a randomized controlled trial. J Am Geriatr Soc. 2012;60:841-8.

77. Yamada M, Higuchi T, Nishiguchi S, Yoshimura K, Kajiwara Y, Aoyama T. Multitarget stepping program in combination with a standardized multicomponent exercise program can prevent falls in community-dwelling older adults: a randomized, controlled trial. J Am Geriatr Soc. 2013;61:1669-75.

78. Yamada M, Tanaka B, Nagai K, Aoyama T, Ichihashi N. Trail-walking exercise and fall risk factors in community-dwelling older adults: preliminary results of a randomized controlled trial. J Am Geriatr Soc. 2010;58:1946-51.

79. Yamada M, Aoyama T, Arai H, Nagai K, Tanaka B, Uemura K, et al. Complex obstacle negotiation exercise can prevent falls in community-dwelling elderly Japanese aged 75 years and older. Geriatr Gerontol Int. 2012;12:461-7.

80. Deeks JJ, Higgins JP, Altman DG. Analysing data and undertaking metaanalyses. Chichester: Wiley; 2008. p. 243-96.

81. Deeks JJ, Altman DG, Bradburn MJ. Statistical methods for examining heterogeneity and combining results from several studies in metaanalysis. Syst Rev Heal Care Meta-Analysis Context 2nd ed London: BMJ Publishing Group; 2008.

82. Freiberger $\mathrm{E}$, Menz HB, Abu-Omar K, Rütten A. Preventing falls in physically active community-dwelling older people: a comparison of two intervention techniques. Gerontology. 2007;53:298-305.

83. Iliffe $S$, Kendrick D, Morris R, Griffin M, Haworth D, Carpenter H, et al. Promoting physical activity in older people in general practice: ProAct65+ cluster randomised controlled trial. Br J Gen Pract. 2015;65:e731-8.

84. Morgan RO, Virnig BA, Duque M, Abdel-Moty E, Devito CA. Low-intensity exercise and reduction of the risk for falls among at-risk elders. J Gerontol A Biol Sci Med Sci. 2004;59:1062-7.

85. Whitehead C, Wundke R, Crotty M, Finucane P. Evidence-based clinical practice in falls prevention: a randomised controlled trial of a falls prevention service. Aust Health Rev. 2003;26:88-97.

86. Means KM, Rodell DE, O'Sullivan PS, Cranford LA. Rehabilitation of elderly fallers: pilot study of a low to moderate intensity exercise program. Arch Phys Med Rehabil. 1996;77:1030-6.

87. Uusi-Rasi K, Patil R, Karinkanta S, Kannus P, Tokola K, Lamberg-Allardt C, et al. A 2-year follow-up after a 2-year RCT with vitamin D and exercise: effects on falls, injurious falls and physical functioning among older women. J Gerontol Ser A. 2017;72:1239-45.

88. Trombetti A, Hars M, Herrmann FR, Kressig RW, Ferrari S, Rizzoli R. Effect of music-based multitask training on gait, balance, and fall risk in elderly people: a randomized controlled trial. Arch Intern Med. 2011;171:525-33.

89. Li F, Harmer P, Fisher KJ, Mcauley E. Tai Chi: improving functional balance and predicting subsequent falls in older persons. Med Sci Sports Exerc. 2004;36:2046-52.

90. Ballard JE, McFarland C, Wallace LS, Holiday DB, Roberson G. The effect of 15 weeks of exercise on balance, leg strength, and reduction in falls in 40 women aged 65 to 89 years. J Am Med Womens Assoc. 2004;59:255-61.

91. Ruffieux J, Mouthon A, Keller M, Wälchli M, Taube W. Behavioral and neural adaptations in response to five weeks of balance training in older adults: a randomized controlled trial. J Negat Results Biomed. 2017;16:11.

92. Loenneke JP, Rossow LM, Fahs CA, Thiebaud RS, Grant Mouser J, Bemben MG. Time-course of muscle growth, and its relationship with muscle strength in both young and older women. Geriatr Gerontol Int. 2017:17:2000-7.

93. Lixandrão ME, Damas F, Chacon-Mikahil MPT, Cavaglieri CR, Ugrinowitsch C, Bottaro M, et al. Time course of resistance training-induced muscle hypertrophy in the elderly. J Strength Cond Res. 2016;30:159-63. 
94. Halvarsson A, Franzén E, Farén E, Olsson E, Oddsson L, Stahle A. Longterm effects of new progressive group balance training for elderly people with increased risk of falling - a randomized controlled trial. Clin Rehabil. 2013:27:450-8.

95. Kamide N, Shiba Y, Shibata H. Effects on balance, falls, and bone mineral density of a home-based exercise program without home visits in community-dwelling elderly women: a randomized controlled trial. J Physiol Anthropol. 2009;28:115-22

96. Liu-Ambrose T, Donaldson MG, Ahamed Y, Graf P, Cook WL, Close J, et al. Otago home-based strength and balance retraining improves executive functioning in older fallers: a randomized controlled trial. J Am Geriatr Soc. 2008;56:1821-30.

97. Logghe IHJ, Zeeuwe PEM, Verhagen AP, Wijnen-Sponselee RMT, Willemsen SP, Bierma-Zeinstra SMA. Lack of effect of tai chi chuan in preventing falls in elderly people living at home: a randomized clinical trial. J Am Geriatr Soc. 2009;57:70-5.

98. Means KM, Rodell DE, O'Sullivan PS. Balance, mobility, and falls among community-dwelling elderly persons. Am J Phys Med Rehabil. 2005;84:238-50.

99. Suzuki T, Kim H, Yoshida H, Ishizaki T. Randomized controlled trial of exercise intervention for the prevention of falls in community-dwelling elderly Japanese women. J Bone Miner Metab. 2004;22:602-11.

100. Weerdesteyn V, Rijken H, Geurts ACH, Smits-Engelsman BCM, Mulder T, Duysens J. A five-week exercise program can reduce falls and improve obstacle avoidance in the elderly. Gerontology. 2006;52:131-41.

101. Lord SR, Ward JA, Williams P, Strudwick M. The effect of a 12-month exercise trial on balance, strength, and falls in older women: a randomized controlled trial. J Am Geriatr Soc. 1995;43:1198-206.

102. Bhatt T, Pai YC. Prevention of slip-related backward balance loss: the effect of session intensity and frequency on long-term retention. Arch Phys Med Rehabil. 2009;90:34-42.

103. Pai YC, Bhatt T, Yang F, Wang E. Perturbation training can reduce community-dwelling older adults' annual fall risk: a randomized controlled trial. J Gerontol - Ser A Biol Sci Med Sci. 2014;69:1586-94.

104. Gerards MHG, McCrum C, Mansfield A, Meijer K. Perturbation-based balance training for falls reduction among older adults: current evidence and implications for clinical practice. Geriatr Gerontol Int. 2017;17:2294-303.

105. Lurie JD, Zagaria AB, Pidgeon DM, Forman JL, Spratt KF. Pilot comparative effectiveness study of surface perturbation treadmill training to prevent falls in older adults. BMC Geriatr. 2013;13:49.

106. Pijnappels $M$, Bobbert MF, Van Dieën JH. Push-off reactions in recovery after tripping discriminate young subjects, older non-fallers and older fallers. Gait Posture. 2005;21:388-94.

107. Maki BE, Mcllroy WE. Change-in-support balance reactions in older persons: an emerging research area of clinical importance. Neurol Clin. 2005;23:751-83.

108. Blakemore S-J, Goodbody SJ, Wolpert DM. Predicting the consequences of our own actions: the role of sensorimotor context estimation. J Neurosci. 1998;18:7511-8.

109. Shadmehr R, Mussa-Ivaldi FA. Adaptive representation of dynamics during learning of a motor task. J Neurosci. 1994;14:3208-24.

110. Yang F, Bhatt T, Pai YC. Generalization of treadmill-slip training to prevent a fall following a sudden (novel) slip in over-ground walking. J Biomech. 2013:46:63-9.

111. Bhatt T, Pai YC. Generalization of gait adaptation for fall prevention: from moveable platform to slippery floor. J Neurophysiol. 2008;101:948-57.

112. Bhatt T, Pai YC. Immediate and latent interlimb transfer of gait stability adaptation following repeated exposure to slips. J Mot Behav. 2008;40:380-90.

113. Hamed A, Bohm S, Mersmann F, Arampatzis A. Exercise dynamic stability under unstable conditions increases muscle strength and balance ability in the elderly. Scand J Med Sci Sports. 2017;28:961-71.

114. Heitkamp HC, Horstmann T, Mayer F, Weller J, Dickhuth HH. Gain in strength and muscular balance after balance training. Int J Sports Med. 2001;22:285-90.

115. Anderson K, Behm DG. Trunk muscle activity increases with unstable squat movements. Can J Appl Physiol. 2005;30:33-45.

116. Morse JM, Tylko SJ, Dixon HA. The patient who falls--and falls again: defining the aged at risk. J Gerontol Nurs. 1985;11:15-8.

117. Zecevic AA, Salmoni AW, Speechley M, Vandervoort AA. Defining a fall and reasons for falling: comparisons among the views of seniors, health care providers, and the research literature. Gerontologist. 2006;46:367-76.
118. Wijlhuizen GJ, Hopman-Rock M, Knook DL, van der Cammen TJ. Automatic registration of falls and other accidents among community dwelling older people: feasibility and reliability of the telephone inquiry system. Int J Inj Control Saf Promot. 2006:13:58-60.

119. Ganz DA, Higashi T, Rubenstein LZ. Monitoring falls in cohort studies of community-dwelling older people: effect of the recall interval. J Am Geriatr Soc. 2005:53:2190-4.

120. Cummings SR, Nevitt MC, Kidd S. Forgetting falls: the limited accuracy of recall of falls in the elderly. J Am Geriatr Soc. 1988;36:613-6.

121. Lim D, Park C, Kim NH, Kim SH, Yu YS. Fall-detection algorithm using 3-axis acceleration: combination with simple threshold and hidden markov model. J Appl Math. 2014;2014:1-8.

122. Kangas $M$, Konttila $A$, Winblad I, Jämsä T. Determination of simple thresholds for accelerometry-based parameters for fall detection. In Proceedings of the 29th Annu Int Conf of the IEEE Eng Med Biol Soc Lyon, France, 22-26 August 2007;1367-1370.

123. Noury N, Barralon P, Virone G, Boissy P, Hamel M, Rumeau P. A smart sensor based on rules and its evaluation in daily routines. Proc 25th Annu Int Conf IEEE Eng Med Biol Soc 2003; 3286-3289.

124. Shany T, Redmond SJ, Narayanan MR, Lovell NH. Sensors-based wearable systems for monitoring of human movement and falls. IEEE Sensors J. 2012:12:658-70.

125. Chaudhuri S, Thompson H, Demiris G. Fall detection devices and their use with older adults: a systematic review. J Geriatr Phys Ther. 2014;37:178-96.

126. Bourke AK, van de Ven PWJ, Chaya AE, OLaighin GM, Nelson J. Testing of a long-term fall detection system incorporated into a custom vest for the elderly. Conf Proc IEEE Eng Med Biol Soc. 2008;2008:2844-7.

127. Garber CE, Blissmer B, Deschenes MR, Franklin BA, Lamonte MJ, Lee IM, et al. Quantity and quality of exercise for developing and maintaining cardiorespiratory, musculoskeletal, and neuromotor fitness in apparently healthy adults: guidance for prescribing exercise. Med Sci Sports Exerc. 2011:43:1334-59.

128. Powell KE, Paluch AE, Blair SN. Physical activity for health: what kind? How much? How intense? On top of what? Annu Rev Public Health. 2011:32:349-65.

129. Sach TH, Logan PA, Coupland CAC, Gladman JRF, Sahota O, Stoner-Hobbs V, et al. Community falls prevention for people who call an emergency ambulance after a fall: an economic evaluation alongside a randomized controlled trial. Age Ageing. 2012;41:635-41.

130. Salminen M, Vahlberg T, Kivelä SL. The long-term effect of a multifactorial fall prevention programme on the incidence of falls requiring medical treatment. Public Health. 2009:123:809-13.

\section{Submit your manuscript to a SpringerOpen ${ }^{\circ}$ journal and benefit from:}

- Convenient online submission

- Rigorous peer review

- Open access: articles freely available online

High visibility within the field

- Retaining the copyright to your article

Submit your next manuscript at $>$ springeropen.com 